\title{
ПАРАЛЕЛЬНЕ ФІЛЬТРУВАННЯ РАНГУ НА ОСНОВІ ІМПУЛЬСНОЇ НЕЙРОННОЇ МЕРЕЖІ ТИПУ “К-WINNERS-TAKE-ALL"
}

\author{
(C) Тимошук П. В., 2017
}

Представлено нейронну мережу (НМ) неперервного часу типу " $K$-winners-take-all” (KWTA), яка ідентифікує $K$ найбільші з-поміж $N$ входів, де керуючий сигнал $1 \leq K<N$. Мережа описусться рівнянням стану 3 розривною правою частиною $i$ вихідним рівнянням. Рівняння стану містить шлейф імпульсів, які описуються сумою дельтафункцій Дірака. Головною перевагою мережі порівняно з іншими близькими аналогами є відсутність обмежень на швидкість збіжності. Описано застосування мережі для паралельного фільтрування рангу. Отримані теоретичні результати проілюстровано прикладом комп'ютерного моделювання, який демонструс ефективність мережі.

Ключові слова: мережа неперервного часу, нейронна мережа (НМ) типу “K-winners-take-all” (KWTA), рівняння стану 3 розривною правою частиною, шлейф імпульсів, дельта-функція Дірака, паралельне фільтрування рангу.

\author{
P. V. Tymoshchuk \\ Lviv Polytechnic National University, \\ Department of Computer Aided Design Systems
}

\section{PARALLEL RANK-ORDER FILTERING BASED ON IMPULSE K-WINNERS-TAKE-ALL NEURAL NETWORK}

(C) Tymoshchuk P., 2017

A continuous-time $K$-winners-take-all (KWTA) neural network (NN) which is capable of identifying the largest $K$ of $N$ inputs, where a command signal $1 \leq K<N$ has presented. The network is described by a state equation with a discontinuous right-hand side and by an output equation. The state equation contains an impulse train defined by a sum of Dirac delta functions. The main advantage of the network is not subject to the intrinsic convergence speed limitations of comparable designs. Application of the network for parallel rank-order filtering has described. Theoretical results are derived and illustrated with computer simulation example that demonstrates the network's performance.

Key words: continuous-time network, $K$-winners-take-all (KWTA) neural network (NN), state equation with a discontinuous right-hand side, impulse train, Dirac delta function, parallel rank-order filtering.

\section{Вступ}

Штучні нейронні мережі (НM), які ще називають штучними нейронними системами, нейрокомп'ютерами, паралельно розподіленими процесорами або моделями зв'язків, $\epsilon$ спробою хоча б частково змоделювати структуру та функції мозку та нейронних систем живих створінь. У 
загальному випадку штучна НМ є інформаційною або такою, що обробляє сигнали, системою, яка складається 3 великої кількості простих оброблювальних елементів. Ці елементи називають штучними нейронами, або просто вузлами. Вони взаємно з'єднуються за допомогою ланок або зв'язків і кооперуються для виконання паралельно розподіленого оброблення даних для розв'язання певної обчислювальної задачі. НМ здатна адаптуватись до умов задачі зміною ваг зв'язків або своєї структури.

HМ типу “ $K$-winners-take-all” (KWTA) призначені для вибору $K$ більших серед $N$ входів, де $1 \leq K<N$ - позитивне ціле число [1-3]. У частковому випадку, коли $K=1$, KWTA зводиться до "winner-takes-all" (WTA) [4, 5]. WTA- i KWTA-властивості є частковими випадками властивостей так званих одночасних рекурентних НM [6]. Такі мережі у загальному випадку потребують навчання і функціонування у режимі, в якому для збіжності необхідне виконання ітерацій.

\section{Огляд літературних джерел}

KWTA-нейронні мережі мають багато застосувань, зокрема, в обробленні даних і сигналів, прийнятті рішень, для розпізнавання образів, у конкурентному навчанні та сортуванні [7]. KWTAмережі використовують у телекомунікаціях [8], системах технічного бачення [9], для фільтрування [10], декодування [11], обробки зображень [12], кластеризації [13], класифікації [14], навігації мобільних роботів i розпізнавання ознак [15]. KWTA-механізми використовуються для розпізнавання явищ та в імпульсних НМ [16].

Запропоновано багато НM для розв'язання WTA- і KWTA-задач [1-5]. Так, наприклад, опис проектування, виготовлення і тестування WTA-функції на основі серійних КМОН-інтегральних схем можна знайти в [17]. KWTA HM неперервного часу, реалізовані в аналоговому апаратному забезпеченні, мають вищу швидкодію, є компактнішими й енергоефективнішими порівняно 3 цифровими реалізаціями [18].

\section{Мета роботи}

У цій статті в KWTA HM неперервного часу необхідно використати шлейф імпульсів, що визначається сумою дельта-функцій Дірака. В результаті цього, на відміну від інших аналогів, для яких траєкторія змінної стану мережі до KWTA-режиму має неперервну лінійну, кусково-лінійну або нелінійну форму, траєкторія змінної стану такої мережі до KWTA-режиму повинна мати ступінчасту форму. Тому, коли період формування імпульсів прямуватиме до нуля, теоретична швидкість збіжності траєкторій змінної стану мережі до WTA-режиму має прямувати до нескінченності. Це означає, що мережа здатна миттєво, без перехідної динаміки ідентифікувати $K$ найбільших серед $N$ входів. Це має бути головною перевагою мережі. Отриману мережу необхідно застосувати для паралельного фільтрування рангу. Потрібно подати результати комп'ютерного моделювання, яке підтверджує й ілюструє теоретичні положення.

\section{Постановка задачі проектування мережі}

Розглянемо вхідний вектор $\boldsymbol{a}=\left(a_{n_{1}}, a_{n_{2}}, \ldots, a_{n_{N}}\right)^{T} \in \mathfrak{R}^{n}, 1<N<\infty \quad 3$ невідомими елементами зі скінченними значеннями. Входи є такими, що їх можна розрізняти і впорядковувати за зменшенням значення згідно з такими нерівностями:

$$
\infty>a_{n_{1}}>a_{n_{2}}>\ldots>a_{n_{N}}>-\infty
$$

де $n_{l}, n_{2}, \ldots, n_{N}$ - невідомі номери першого найбільшого входу, другого найбільшого входу і т. д. аж до $N$-го найбільшого входу. Необхідно спроектувати таку НМ, яка здатна миттєво, без перехідної динаміки ідентифікувати $K$ найбільших з цих входів, які називаються переможцями. Спроектована мережа повинна обробляти вхідний вектор $\boldsymbol{a}$ так, щоб отримувати такий вихідний вектор $\boldsymbol{b}=\left(b_{n_{1}}, b_{n_{2}}, \ldots, b_{n_{N}}\right)^{T}$, щоб задовольнялась КWTА-властивість [1]:

$$
b_{n_{i}}>0, i=1,2, \ldots, K ; b_{n_{j}}<0, j=K+1, K+2, \ldots, N .
$$


Крім цього, має бути можливість одержання вихідних сигналів НМ у такій формі [19]:

$$
d_{n_{i}}=1, i=1,2, \ldots, K ; d_{n_{j}}=0, j=K+1, K+2, \ldots, N .
$$

Необхідно дослідити стабільність і збіжність траєкторій змінної стану мережі до KWTAрежиму.

Зауважимо, що у випадку використання вихідних сигналів мережі (3) будуть ідентифікуватись лише $K$ переможців серед $N$ входів. Інформації стосовно впорядкування входів за величиною, яка може бути використана надалі, наприклад, для розв'язання задач класифікації, кластеризації тощо, отримано не буде [20].

\section{Імпульсна мережа неперервного часу}

Спростимо аналогову KWTA-мережу неперервного часу, запропоновану в [2], і введемо до іiі правої частини імпульси у формі дельта-функцій Дірака [21], описавши таку мережу рівнянням стану:

і вихідним рівнянням

$$
\frac{d x}{d t}=r D(x) \sum_{l=0}^{m} \delta\left(t-t_{l}\right)
$$

$$
b_{n_{k}}=a_{n_{k}}-x, k=1,2, \ldots, N \text {, }
$$

де

$$
D(x)=\sum_{k=1}^{N} S_{k}(x)-K
$$

- функція різниці між отриманою і необхідною кількістю позитивних виходів,

$$
S_{k}(x)=\left\{\begin{array}{lc}
1, & \text { if } \quad a_{n_{k}}-x>0 \\
0, & \text { otherwise }
\end{array}\right.
$$

- ступінчаста функція,

$$
\delta\left(t-t_{l}\right)=\left\{\begin{array}{ccc}
+\infty, & \text { if } \quad t=t_{l} \\
0, & \text { if } & t \neq t_{l}
\end{array}\right.
$$

- імпульс у формі дельта-функції Дірака; $\sum_{l=l}^{m} \delta\left(t-t_{l}\right)$ - шлейф імпульсів; $t_{l}$ - стала часу формування імпульсів; $m$ - кількість імпульсів, необхідних для досягнення збіжності пошукового процесу до KWTA-режиму; $r$ - роздільна здатність мережі.

На відміну від аналогів [3] з неперервною нелінійною траєкторією змінної стану $x$, мережа має ступінчасту траєкторію змінної стану $x$. Тому вона спроможна досягати теоретично будь-якої скінченної швидкості обробки входів, яка визначається періодом формування імпульсів. Якщо цей період прямує до нуля, час оброблення мережею входів також прямує до нуля. Це - головна перевага мережі. Практична швидкість обробки входів такою мережею обмежується ії програмною або апаратною реалізацією. Зокрема, програмна реалізація мережі характеризується обмеженою точністю обчислень. У випадку апаратної реалізації обмеженнями є скінченна швидкодія компаратора, неідеальності інтегратора, неузгодженість тощо [22].

\section{Паралельне фільтрування рангу}

Надалі посилатимемось на мережу зі шлейфом імпульсів з частковими значеннями $K$. Тому використовуватимемо терміни № WTA-мережа для $K=$ № для довільного часткового значення №. Фільтри рангу (ФР) відомі як нелінійні фільтри, що ідентифікують у часовій та просторовій областях сигнали $K$-го рангу серед елементів $N$-вимірного вектора сигналів. ФР застосовуються у багатьох сферах, зокрема, для оброблення зображень, сигналів i мови, видалення шуму, в комп'ютерній томографії, для розпізнавання образів, кодування, у цифровому телебаченні тощо. Запропоновано різні методи проектування ФР [3]. Зокрема, аналоговий ФР, побудований на ВІС за допомогою двох так званих “multiple-winners-take-all”-блоків, які функціонують паралельно, 
описано в [10]. В [3] для вибору входу К-го порядку використовується KWTA-мережа $3 K$ переможцями паралельно з іншою (K-1) WTA-мережею з $K-1$ переможцями.

Вихідний сигнал ФР $g_{k}, k=1,2,3, \ldots, N$ можна отримати за допомогою системи алгебраїчних рівнянь

$$
c_{1}=a^{T} S^{1}, c_{K+1}=a^{T}\left(S^{K+1}-S^{K}\right),
$$

де елементи К-го стовпчика $S^{K}=\left[S_{1}^{K}, S_{2}^{K}, \ldots, S_{N}^{K}\right]^{T}, K=1,2, \ldots . ., N$-1 сортувальної матриці визначаються ступінчастими функціями (7), з використанням рівняння станів (4) KWTA-мережі. Однак, якщо ФР, описаний за допомогою (9), застосовується для оброблення нестаціонарних сигналів, його вихідні сигнали у часових точках, де порушується умова (1), можуть демонструвати так звані “вібрації”. Тому для підвищення ефективності ФР необхідно розглянути випадок рівності двох або більшої кількості входів. Якщо такі входи належать до $K$ переможців або до $N-K$ переможених, тоді виходи мережі прямують до KWTA-режиму. Однак у випадку, коли мережа має розрізняти вхідні сигнали з рівними максимальними значеннями і розщеплювати їх у позитивну i негативну площини, якщо $K$ найбільших входів не існують, тоді отримують вихідні сигнали мережі, які не мають KWTA-властивості. Зокрема, виходи мережі осцилюють у часових точках, у яких порушуються нерівності (1), тобто у яких входи дорівнюють один одному. Для видалення таких осциляцій вираз (9) можна узагальнити на випадок оброблення змінних у часі вхідних сигналів, які дорівнюють один одному у деяких часових точках. Тому для підвищення ефективності ФР узагальнимо вираз (9) до такої форми:

$$
\begin{aligned}
& g_{I}=a^{T} S^{l} \text {, якщо } D^{l}(x)=0, \\
& d g_{1} / d t=0, g_{1}(0)=0 \text { інакше; } \\
& g_{K+1}=a^{T}\left(S^{K+1}-S^{K}\right), \text { якщо } D^{K+1}(x)=0, D^{K}(x)=0, \\
& d g_{K+1} / d t=0, g_{K+1}(0)=0 \text { інакше, }
\end{aligned}
$$

де $D^{K}(x)$ - різницеве рівняння (6) при $K$ переможцях і $K=1,2,3, \ldots, N-1, g_{K}(0)=0, g_{K+1}(0)=0$ початкові умови. У встановленому KWTA-режимі система алгебро-диференційних рівнянь (10) зводиться до системи алгебраїчних рівнянь (9), яка є іiі частковим випадком. Для визначення першого найбільшого вхідного сигналу використовується 1WTA-мережа. $(\mathrm{K}+1)$ WTA-мережа і KWTA-мережа паралельно застосовуються для ідентифікації $K+1$ максимальних вхідних сигналів. Для визначення $N$-го найбільшого вхідного сигналу використовувати NWTA-мережі не потрібно, оскільки можна задати $S^{N}=[1,1, \ldots, 1]^{T}$. У перехідному режимі вихідні сигнали ФР визначають за допомогою виродженого диференційного рівняння системи (10).

Приклад. Продемонструємо ефективність описаного ФР, використавши систему алгебродиференційних рівнянь (10) і рівняння станів (4). Використаємо множину неперервних у часі входів $a_{n_{k}}=A \sin (\omega t+k \phi)+d+\chi \quad(k=1,2, \ldots, N)$, де $\omega-$ кутова частота; $\varphi-$ зсув фази; $d-$ нахил; $\chi-$ адитивний шум для $r=0.05, A=15, \omega=2 \pi \times 10^{12}$, яка $\epsilon$ дуже високою кутовою частотою, $\varphi=0.2 \pi$, $d=3, x_{0}=0, \tau=5 \times 10^{-5} \mathrm{ps}$, випадкових сигналів $\chi$, однорідно розподілених 3 максимальним $\mathrm{i}$ мінімальним значеннями 0.2 i -0.2 відповідно і нульовим розкидом для непарних входів $\mathrm{i}$ нормально розподілених з нульовим середнім і дисперсією, яка дорівнює 0.01 , для парних входів. Джерело імпульсів реалізуємо за допомогою послідовного сполучення генератора імпульсів, диференціатора і блоків абсолютного значення. Динаміка відфільтрованого вихідного сигналу $g_{5}$, обчисленого за допомогою системи алгебраїчних рівнянь (9) і системи алгебро-диференційних рівнянь (10), 3 використанням ODE1 3 автоматичним вибором фіксованого розміру кроку, зображена на рисунку а і б відповідно. Як можна побачити з цих рисунків, вихідні сигнали ФР, що описується системою алгебраїчних рівнянь (9) і рівнянням стану (4), демонструють “вібрації” у часових точках рівних входів, тобто у яких нерівності (1) не задовольняються. Виходи ФР, описаного системою алгебро-диференційних рівнянь (10) і рівнянням станів (4), коректно ідентифікують п'ятий вхід високої частоти без будь-якої вібрації. Зауважимо, що кутова частота 
змінних у часі сигналів, оброблених за допомогою цього ФР, на дев’ять порядків вища від частоти сигналів аналога 3 [3].

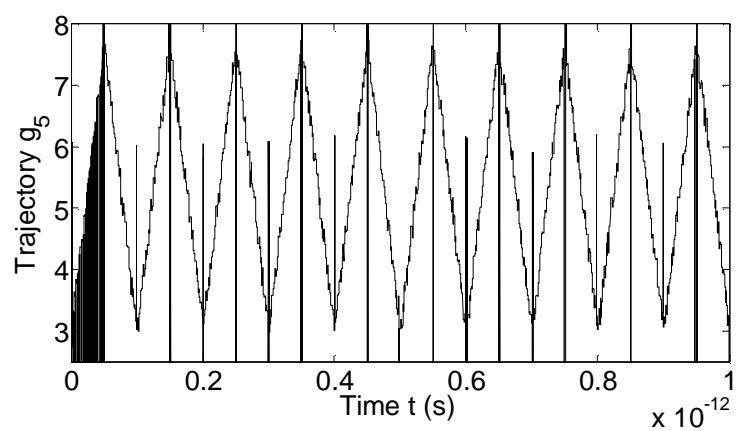

a

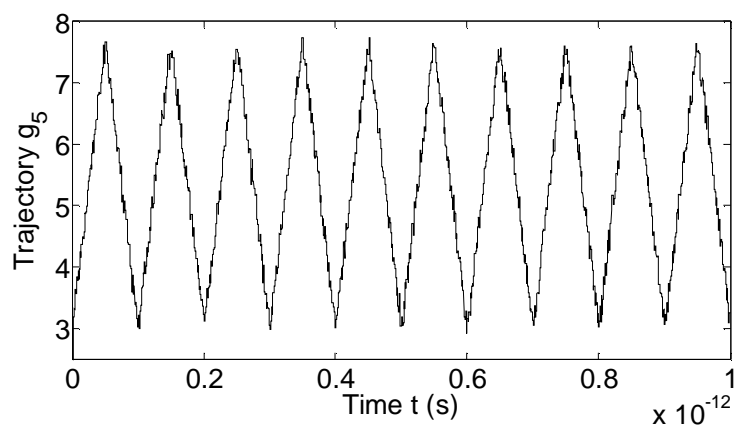

$\mathrm{b}$

Ілюстрачія до прикладу: а - динаміка відфільтрованого вихідного сигналу $g_{5}$ ФР, щуо описується системою алгебрайчних рівнянь (9) $i$ рівнянням станів (4); $b$ - траєкторія виходу $g_{5}$ $Ф Р$, який описується системою алгебро-диферениійних рівнянь (10) і рівнянням станів (4)

\section{Висновки}

У статті описано аналогову імпульсну KWTA HM неперервного часу. Мережа вибирає $K$ максимальних серед будь-яких $N$ невідомих входів зі скінченними значеннями, які можна розрізняти, розміщеними у невідомому діапазоні, де $l \leq K<N$. На відміну від інших аналогів, траєкторії змінної станів мережі мають кусково-постійну, тобто ступінчасту форму. Тому встановлені KWTA-режими у мережі можуть отримуватись теоретично миттєво, якщо період формування імпульсів прямує до нуля. Отже, така мережа може ідентифікувати $K$ найбільших серед $N$ входів без перехідної динаміки. Подано результати застосування мережі для паралельного фільтрування рангу, які свідчать про його високу ефективність.

1. Majani E., Erlanson R., and Abu-Mostafa Y. On the k-winners-take-all network I// in Advances in Neural Information Processing Systems 1, R. P. Lippmann, J. E. Moody, and D. S. Touretzky, Eds. San Mateo, CA: Morgan Kaufmann, 1989, pp. 634-642. 2. Tymoshchuk P. A dynamic K-winners take all analog neural circuit // in Proc. IV ${ }^{\text {th }}$ Int. Conf. "Perspective technologies and methods in MEMS design", Lviv-Polyana, Ukraine, 2008, pp. 13-18. 3. Wang J. Analysis and design of a k-winners-take-all network with a single state variable and the Heaviside step activation function // IEEE Trans. Neural Netw., vol. 21, no. 9, P. 1496-1506, Sept. 2010. 4. Lippmann R. P. An introduction to computing with neural nets // IEEE Acoustics, Speech and Signal Processing Magazine, vol. 3, no. 4, pp. 4-22, Apr. 1987. 5. Tymoshchuk P. and Kaszkurewicz E. A winner-take all circuit using neural networks as building blocks // Neurocomputing, vol. 64, pp. 375-396, Mar. 2005. 6. Wunsch D. C. The cellular simultaneous recurrent network adaptive critic design for the generalized maze problem has a simple closed-form solution // in Proc. Int. Joint Conf. Neural Netw., Jul. 2000, P. 79-82. 7. Atkins M. Sorting by Hopfield nets, in Proc. 
Int. Joint Conf. Neural Netw., Jun. 1989, - P. 65-68. 8. Binh L. N. and Chong H. C. A neural-network contention controller for packet switching networks // IEEE Trans. Neural Netw. vol. 6, no. 6, P. 14021410, Nov. 1995. 9. Itti L., Koch C., and Niebur E. A network of saliency-based visual attention for rapid scene analysis // IEEE Trans. Pattern Analysis and Machine Intelligence, vol. 20, no. 11, P. 1254 - 1259, Nov. 1998. 10. Cilingiroglu U. and Dake T. L. E. Rank-order filter design with a sampled-analog multiplewinners-take-all core // IEEE J. Solid-State Circuits, vol. 37, no. 2, pp. 978-984, Aug. 2002. 11. Erlanson R. and Abu-Mostafa Y. Analog neural networks as decoders // in Advances in Neural Information Processing Systems, vol. 1, R. P. Lippmann, J. E. Moody, and D. S. Touretzky, Eds. San Mateo, CA: Morgan Kaufmann, 1991. 12. Fish A., Akselrod D., and Yadid-Pecht O. High precision image centroid computation via an adaptive $k$-winner-take-all circuit in conjunction with a dynamic element matching algorithm for star tracking applications // Analog Integrated Circuits and Signal Processing, vol. 39, no. 3, P. 251-266, Jun. 2004. 13. Jain B. J. and Wysotzki F. Central clustering of attributed graphs // Machine Learning, vol. 56, no. 1, pp. 169-207, Jul. 2004. 14. Chartier S., Giguere G., Langlois D. and Sioufi R. Bidirectional associative memories, self-organizing maps and $k$-winners-take-all; uniting feature extraction and topological principles // in Proc. Int. Joint Conf. Neural Netw., Jun. 2009, pp. 503-510. 15. G. N. DeSouza and A. C. Zak, "Vision for mobile robot navigation: a survey," IEEE Trans. Pattern Analysis and Machine Intelligence, vol. 24, no. 2, p. 237-267, Feb. 2002. 16. O'Reilly R. C. and Munakata $Y$. Computational Explorations in Cognitive Neuroscience: Understanding the Mind by Simulating the Brain. Cambridge, MA: MIT Press, 2000. 17. Lazzaro J., Ryckebusch S., Mahowald M. A., and Mead C. A. Winner-take-all networks of $O(N)$ complexity // in Advances in Neural Information Processing Systems 1, R. P. Lippmann, J. E. Moody, and D. S. Touretzky, Eds. San Mateo, CA: Morgan Kaufmann, 1989, pp. 703-711. 18. Sekerkiran B. and Cilingiroglu U. A CMOS K-winners-take-all circuits with O(N) complexity // IEEE Trans. Circuits Syst. II, vol. 46, no. 1, p. 1-5, Jan. 1999. 19. Maass W. Neural computation with winner-take-all as the only nonlinear operation // in Advances in Information Processing Systems, vol. 12, S. A. Solla, T. K. Leen, and K.-R. Mueller, Eds. Cambridge, MA: MIT Press, 2000, pp. 293-299. 20. Calvert B. D. and Marinov C. A. Another K-winners-take-all analog neural network // IEEE Trans. Neural Netw., vol. 4, no. 1, P. 829-838, Jul. 2000. 21. Wang J. Analogue winner-take-all neural networks for determining maximum and minimum signals," Int. J. Electron., vol. 77, no. 3, p. 355-367, Mar. 1994. 22. Cichocki A. and Unbehauen R. Neural Networks for Optimization and Signal Processing. New York, NY, USA: Wiley, 1993. 